\title{
Synthesis and Structural Studies of an Organic Complex and its Association with BSA
}

\author{
Fa-Yan Meng, Sheng-Rong Yu, Li-Xi Liang, Xue-Ping Zhong, Li Wang, Jin-Mei Zhu, and Cui-Wu Lin* \\ College of Chemistry and Chemical Engineering, Guangxi University, Guangxi 530004, People's Republic of China \\ *E-mail: cuiwulin@yahoo.com.cn \\ Received May 6, 2011, Accepted May 19, 2011
}

\begin{abstract}
The self-assembly of one novel organic complex based on chlorogenic acid (HCA) and 2,2'-bipyridine (2,2'bipy) has been synthesized and characterized. The complex achieved by hydrogen-bonding interactions, adopted a 1:1 stoichiometry in a solid state. The proton transfer occurred from the carboxyl oxygen to the aromatic nitrogen atom to form salts $\mathrm{CA} \cdot\left(2,2^{\prime}\right.$-Hbipy), the 2,2'-Hbipy molecule individually occupies the pseudo-tetragonum that is formed with $\mathrm{CA}$. In this paper, the interactions of CA.(2,2'-Hbipy) with bovine serum albumin (BSA) were studied by fluorescence spectrometry. For CA·(2,2'-Hbipy), HCA and 2,2'-bipy, the average quenching constants for BSA were $2.4384 \times 10^{4}, 4.653 \times 10^{3}$, and $3.059 \times 10^{3} \mathrm{~L} \cdot \mathrm{mol}^{-1}$, respectively. The mechanism for protein fluorescence quenching is apparently governed by a static quenching process. The Stern-Volmer quenching constants and corresponding thermodynamic parameters $\Delta H, \Delta G$ and $\Delta S$ were calculated. The binding constants and the number of binding sites were also investigated. The conformational changes of BSA were observed from synchronous fluorescence spectra.
\end{abstract}

Key Words : Bovine serum albumin, Organic complex, Chlorogenic acid, Fluorescence quenching, 2,2'Bipyridine

\section{Introduction}

Pharmaceutical research involving an active pharmaceutical ingredient (API) often deals with various solid forms, such as polymorphs, host-guest complexes, network solids, co-crystals, solvates (including hydrates), and organic complex (salt). ${ }^{1}$

Co-crystals are a well-known ${ }^{2}$ but relatively unexplored class of compounds. They can be defined as multiplecomponent crystal systems which were usually based on hydrogen bonds or non-covalent interactions. ${ }^{3}$ The study of co-crystal is a topic of current interest ${ }^{4}$ because they are an important tool for improving the physical properties of active pharmaceutical ingredients, such as solubility, hygroscopicity, thermal stability, and processability in the pharmaceutical industry. ${ }^{5}$ Although the practical applications of crystal engineering and supramolecular synthesis in pharmaceutical sciences are still emerging areas of research, cultivating co-crystals is becoming an accepted approach for creating solid dosage forms. ${ }^{6,7}$

Similar to co-crystals, organic salts are also a multi-component system that can have different physical and chemical properties. In salts, protons are transferred between the components. Salts make APIs more bio-available, but more than $30 \%$ of pharmaceutical compounds lack suitable functionality for salt formation. ${ }^{1}$ So, to formulate good physical and chemical properties of pharmaceutical salt have been the focusing area for decades.

Serum albumin is known to act as a transport protein that binds to a wide variety of compounds, including many drugs, hormones, bilirubin, and fatty acids. ${ }^{89}$ In this paper, we choose BSA as the protein model for that human albumins and BSA are homologous proteins, and its medical importance, stability, binding, and transport properties, as well as the fact that all other studies consistently confirm.

Previous studies have investigated the binding of BSA to small organic molecules ${ }^{10}$ and metal-organic complexes, ${ }^{11}$ which show its interactions with drugs can have a strong influence on the free concentrations of drugs in plasma and the pharmacologic and pharmacokinetic properties of a drug. ${ }^{12}$ The methods always involve fluorescence quenching, equilibrium dialysis, ultrafiltration, isothermal titration calorimetry, heteronuclear 2-D NMR, and reversed-phase liquid chromatography. These small molecules are stabilized when binding to BSA through a series of weak interactions, such as the $\pi$-stacking interactions, hydrogen-bonding, and van der Waals interactions. ${ }^{13}$

This report will use quenching measurements of albumin fluorescence to determine the interaction between organic complex and BSA, which should reveal the accessibility of quenchers to albumin's fluorophores, help to better understand albumin binding mechanisms and the nature of the binding phenomenon to organic complex [8(b)].

Chlorogenic acid, an important active component in traditional Chinese medicine, exists widely in numerous plant species ${ }^{14}$ and may interact covalently or non-covalently with BSA. ${ }^{15,16}$ To the best of our knowledge, few crystals of chlorogenic acid have been reported, ${ }^{17,18}$ and the interaction between an organic complex based on chlorogenic acid and biological macromolecules has not been reported until now.

To get more information about the binding force quality and the mechanism of the interactions between organic complex and the biological macromolecules, we synthesized a organic complex based on chlorogenic acid with 2,2'-bipy 
<smiles>O=C(O)OC1CC(O)(C(=O)O)CC(O)C1O</smiles>

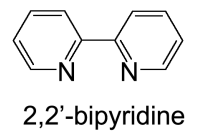

Scheme 1. Molecular structures of chlorogenic acid and 2,2'bipyridine.

(Scheme 1) and studied the interaction between the crystal and BSA. By analyzing the fluorescence parameters, we obtained much information about the interactive features and the structural changes in the bio-macromolecules.

\section{Experimental}

Materials. BSA was obtained from Shanghai Yuanju Biological Technology Co. Ltd. (China). The chlorogenic acid was extracted from the Blumea riparia (B1.) DC.. ${ }^{19}$ BSA stock solution, $1.0 \times 10^{-4} \mathrm{~mol} \mathrm{~L}^{-1}$, was prepared in 0.1 mol L ${ }^{-1}$ Tris- $\mathrm{HCl}$ buffer solution $(\mathrm{pH}=7.4)$ and then stored in refrigerator prior to use. Compounds stock solution, were prepared by dissolving the drugs (CA-(2,2'-Hbipy), HCA and 2,2'-bipy) in the same buffer. These solutions $\left(1 \times 10^{-3}\right.$ mol $\mathrm{L}^{-1}$ ) are stable when kept under $2-5^{\circ} \mathrm{C}$ ). All other chemicals were commercial materials of analytical grade and were used without purification, and double distilled water was used throughout.

Apparatus and Measurements. The X-ray diffraction intensity data for the crystal was collected on a Bruker SMART CCD diffractometer equipped with a graphitemonochromated $\mathrm{MoK} \alpha$ radiation source $(\lambda=0.71073 \AA)$ at 298(2) K. All absorption corrections were performed with SADABS program. ${ }^{20}$ The structure was solved by direct methods and rened with full-matrix least-squares and expanded using Fourier techniques. Anisotropic thermal parameters were assigned to all non-hydrogen atoms. All the $\mathrm{H}$ atoms bonded to Carbon atoms were located at the ideal positions with the $\mathrm{C}-\mathrm{H}=0.93 \AA$ (aromatic), $0.97 \AA$ (methylene) and the thermal factors being set 1.2 times (for aromatic and methylene) or 1.5 times (methyl) of their carrier atoms.
$\mathrm{H}$ atoms bonded to $\mathrm{N}$ and $\mathrm{O}$ atoms were found from the difference maps with the constraints of $\mathrm{N}-\mathrm{H}=0.86(1) \AA$ and $\mathrm{O}-\mathrm{H}=0.82(1) \AA$ and the thermal factors being set $k$ times of their carrier atoms $(k=1.2$ for $\mathrm{N}$ and 1.5 for $\mathrm{O}$ atoms, respectively). All calculations were performed using SHELXTL-97 program. $^{21}$ The crystallographic data was summarized in Tables S1.

The fluorescence measurements were carried out by RF-5301PC model spectrofluorometer (Shimadzu, Japan) equipped with a xenon lamp source and and a $1.0 \mathrm{~cm}$ cell. Fluorescence spectra were obtained at excitation wavelength of $295 \mathrm{~nm}$, with the excitation and emission slit widths set at $3 \mathrm{~nm}$. And the range of synchronous scanning was: $\Delta \lambda=15$ $\mathrm{nm} ; \Delta \lambda=60 \mathrm{~nm}$, with the excitation and emission slit widths at $3 \mathrm{~nm}$ and $3 \mathrm{~nm}$. All $\mathrm{pH}$ measurements were made with a pHs-3C digital pH meter (Shanghai Leici Device Works, China) with a combined glass-calomel electrode. The temperature was controlled by a water-bath and temperatures were kept in a certain range $\left(\mathrm{T} \pm 0.1{ }^{\circ} \mathrm{C}\right)$ throughout the experiment.

\section{Results and Discussion}

Description of the Structure. The organic complex of CA.(2,2'-Hbipy) forms in the space group $P 2(1)$ with the asymmetric unit. Single crystals of the CA.(2,2'-Hbipy) complex were obtained from an ethanol solution via slow evaporation of the solvent. ${ }^{22}$ The proton transfer occurred from the carboxyl oxygen to the aromatic nitrogen atom to form salts (Fig. 1). Extended left-handed helical chains were formed (Fig. 2) by hydrogen bonds [O 7 $\cdots \mathrm{O} 4, \mathrm{H} 7 \mathrm{o} \cdots \mathrm{O} 4$, O7H70 $\cdots \mathrm{O} 4(-\mathrm{x}, \mathrm{y}+1 / 2,-\mathrm{z}+1): 2.666(11), 1.88 \AA, 160.1^{\circ}$; O6 $\cdots \mathrm{O} 4, \mathrm{H}_{\mathrm{O}} \cdots \mathrm{O} 4(-\mathrm{x}, \mathrm{y}+1 / 2,-\mathrm{z}+1): 2.772(11), 1.99(9) \AA$, 159(8) ${ }^{\circ}$; O6 $\cdots \mathrm{O} 8, \mathrm{H} 66_{0} \cdots \mathrm{O} 8$ (-x, y+1/2, $\left.-\mathrm{z}+1\right)$ : 2.894(11), 2.33(8) $\left.\AA, 126(7)^{\circ}\right]$. The adjacent chains were connected and aligned along the $b$-axis via $\mathrm{O}-\mathrm{H} \cdots \mathrm{O}$ hydrogen bonding [O $3 \cdots \mathrm{O} 5, \mathrm{H} 33_{\mathrm{O}} \cdots \mathrm{O} 5, \mathrm{O} 3-\mathrm{H} 33_{\mathrm{O}} \cdots \mathrm{O} 5(\mathrm{x}+1, \mathrm{y}, \mathrm{z}): 2.772(11)$, $1.97 \AA, 165.1^{\circ}$; O9 $\cdots \mathrm{O} 4, \mathrm{H} 9{ }_{\mathrm{O}} \cdots \mathrm{O} 4, \mathrm{O} 9-\mathrm{H} 6_{\mathrm{O}} \cdots \mathrm{O} 4(\mathrm{x}+1, \mathrm{y}, \mathrm{z})$ : $\left.2.715(11), 2.45 \AA, 100.1^{\circ}\right]$ interactions, forming a twodimensional supra-molecular sheet, as shown in Figure 3(a). An interesting structural feature of the crystal was that each

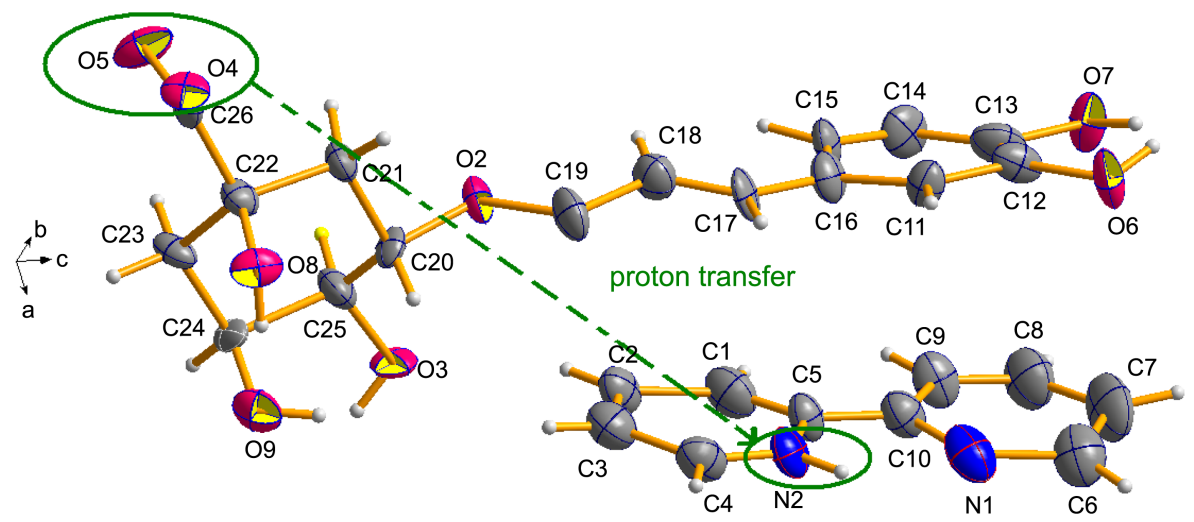

Figure 1. Atomic numbering scheme for CA-(2,2'-Hbipy) with displacement ellipsoids at the $50 \%$ probability level. The highlighted region depicts the proton transfer region in the molecular complex. 
(a)

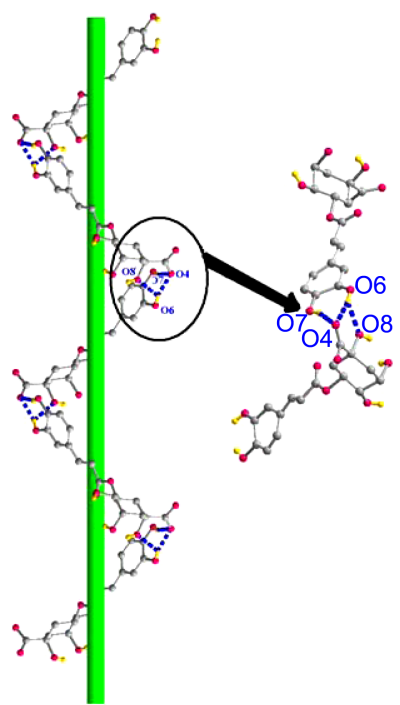

(b)

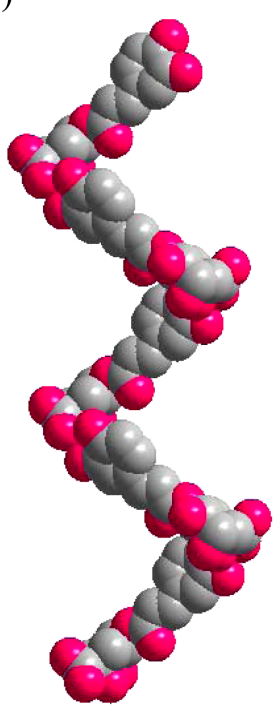

Figure 2. (a) View of the 1D supramolecular helical chain formed by multiple $\mathrm{O}-\mathrm{H} \cdots \mathrm{O}$ hydrogen bonds in the crystal structure of CA.(2,2'-Hbipy); (b) Space-filling representation of the helices.

(a)

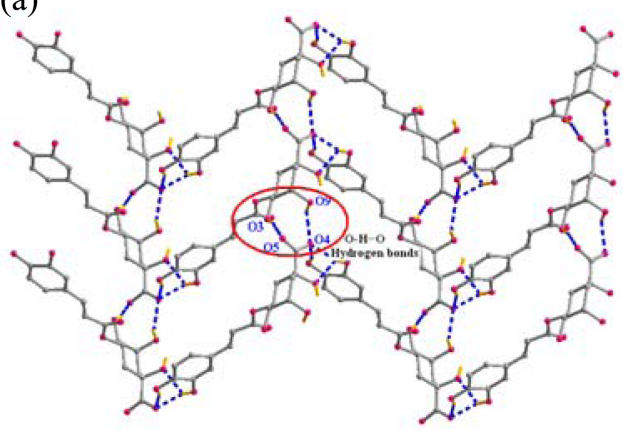

(b)

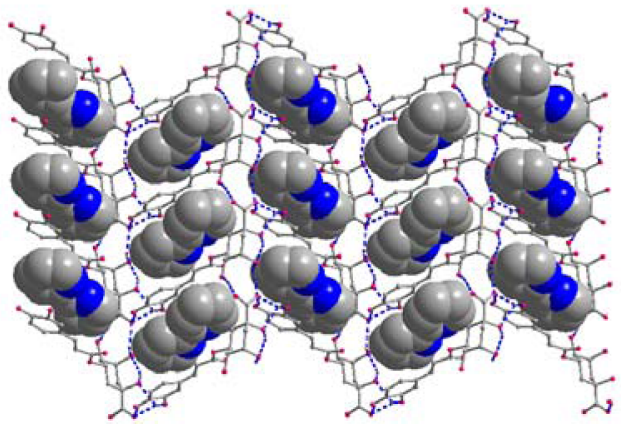

Figure 3. (a) Supramolecular sheet formed by inter-chain $\mathrm{O}-\mathrm{H} \cdots \mathrm{O}$ hydrogen bonding between the CA; (b) 2,2'-Hbipy fill of the pseudo-tetragonum of the 2D sheet.

pseudo-tetragonum in the $2 \mathrm{D}$ sheet was filled by a $2,2^{\prime}-$ Hbipy molecule (Fig. 3(b)), each 2,2'-Hbipy molecule was fixed by only one $\mathrm{N}-\mathrm{H} \cdots \mathrm{O}\left[\mathrm{N} 2 \cdots \mathrm{O} 5, \mathrm{H} 22_{\mathrm{N}} \cdots \mathrm{O} 5, \mathrm{~N} 2-\mathrm{H} 22_{\mathrm{N}} \cdots \mathrm{O} 5\right.$ $\left.(\mathrm{x}+1, \mathrm{y}, \mathrm{z}+1): 2.750(12), 2.13 \AA, 128.5^{\circ}\right]$ hydrogen bond between the carboxyl oxygen and the 2,2'-bipy nitrogen atom to form 3D architecture .

Fluorescence Quenching Spectra Study. Proteins are considered to have intrinsic fluorescence due to the presence

(a)

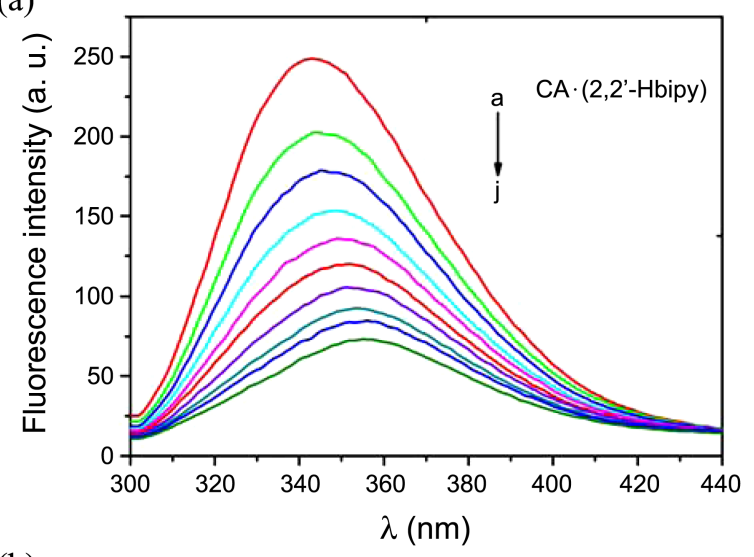

(b)

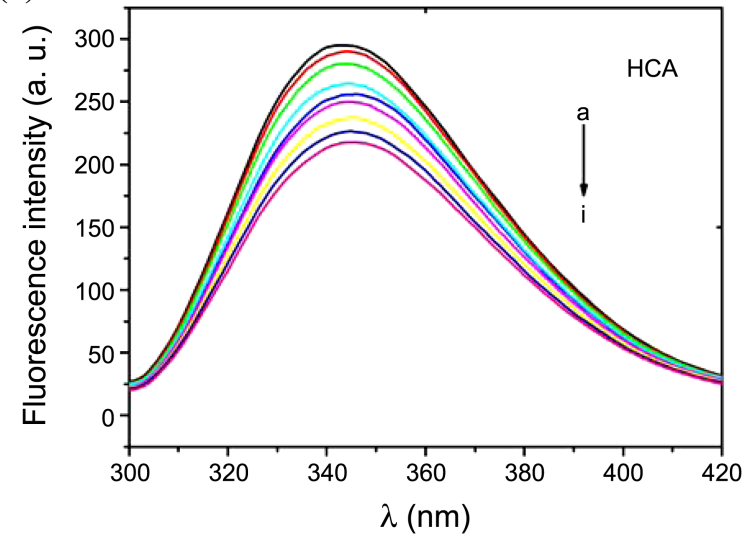

(c)

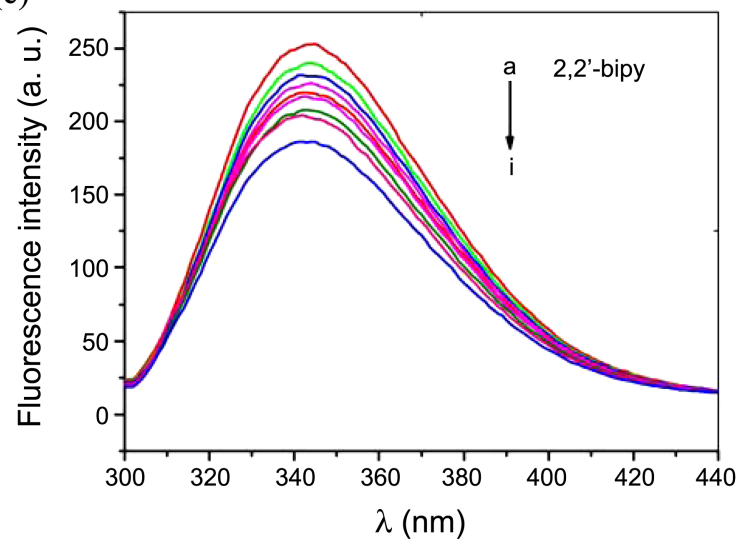

Figure 4. The quenching effect of CA-(2,2'-Hbipy) (a); HCA (b) and 2,2'-bipy (c) on BSA fluorescence intensity. $\lambda_{\mathrm{ex}}=295 \mathrm{~nm}$; BSA, $5.00 \times 10^{-6} \mathrm{~mol} \cdot \mathrm{L}^{-1}$; CA $2,22^{\prime}$-Hbipy, a-j: 0.00, 0.50, 1.00 , 1.50, 2.00, $2.503 .00,3.504 .00$ and $4.50 \times 10^{-5} \mathrm{~mol} \cdot \mathrm{L}^{-1}$; HCA, a-i: $0.00,2.50,5.00,7.50,10.00,12.50,15.00$ and $17.5 \times 10^{-5} \mathrm{~mol} \cdot \mathrm{L}^{-1}$; 2,2'-bipy, a-i: $0.00,0.50,1.00,1.50,2.00,2.50,3.00,3.50$ and $4.00 \times 10^{-5} \mathrm{~mol} \cdot \mathrm{L}^{-1}$.

of amino acids, mainly tryptophan, tyrosine and phenylalanine. ${ }^{23}$ BSA solutions excited at $295 \mathrm{~nm}$ emit fluorescence attributable mainly to tryptophan residues. Figure 4 shows the fluorescence quenching spectra of solutions containing a BSA fixed concentration and different concentrations of each of the studied compounds (CA'(2,2'-Hbipy), HCA, and 2,2'-bipy). The fluorescence intensity of BSA decreased regularly with an increase in the concentration of the com- 
plexes, which indicates that the studied compounds can bind to BSA. An obviously red shifts for the combination of CA.(2,2'-Hbipy) and CA with BSA could be deduced that conformational changes induced by the interaction lead to the polarity around the Trp residues was increased and the hydrophobicity was decreased, which agrees with a recent study that the tertiary structure of proteins changed after binding with the other compounds. ${ }^{24}$ The effect of 2,2'-bipy on the fluorescence spectra of BSA, there was weak blue shift of $\lambda \mathrm{em}$, this means that the molecular conformation of the protein was effected, which shown that the tertiary structure of proteins changed after binding with the 2,2'bipy, while the secondary structure remained intact.

Fluorescence quenching is described by the Stern-Volmer equation $^{25}$ :

$$
\begin{gathered}
F_{0} / F=1+K_{\mathrm{q}} \tau_{0}[Q]=1+K_{\mathrm{SV}}[Q] \\
K_{\mathrm{q}}=K_{\mathrm{SV}} / \tau_{0}
\end{gathered}
$$

where $F_{0}$ and $F$ are the fluorescence intensities before and after the addition of the quencher, respectively. $K_{\mathrm{q}}, K_{\mathrm{Sv}}, \tau_{0}$ and $[Q]$ are the quenching rate constant of the bio-molecule, the Stern-Volmer dynamic quenching constant, the average life-time of the bio-molecule without the quencher $\left(\tau_{0}=10^{-8}\right.$ $\mathrm{s}^{26}$ ), and the concentration of the quencher. Fluorescence quenching could proceed via different mechanisms, usually classified as dynamic quenching and static quenching. For dynamic quenching, the maximum scatter collision quenching constant of various quenchers with the biopolymer is $2.0 \times 10^{10} \mathrm{~L} \cdot \mathrm{mol}^{-1} \cdot \mathrm{s}^{-1}$. If the $K_{\mathrm{SV}}$ is much greater than $2.0 \times 10^{10} \mathrm{~L} \cdot \mathrm{mol}^{-1} \cdot \mathrm{s}^{-1}$, it can be concluded that the quenching is not initiated by dynamic quenching, but probably partly by static quenching resulted from the formation of drug-BSA complex.

For the complex-BSA systems, the Stern-Volmer graphs are presented in Figure 5 and the values of $K_{\mathrm{SV}}$ and $K_{\mathrm{q}}$ $\left(=K_{\mathrm{SV}} / \tau_{0}\right)$ obtained from the plots at $24{ }^{\circ} \mathrm{C}$ are shown in Table 1. The values of $K_{\mathrm{q}}$ are larger than $2.0 \times 10^{10}$ $\mathrm{L} \cdot \mathrm{mol}^{-1} \cdot \mathrm{s}^{-1}$ for a variety of quenchers with biopolymers, ${ }^{27}$ which indicated that the probable quenching mechanism of fluorescence of BSA by complex was not initiated by

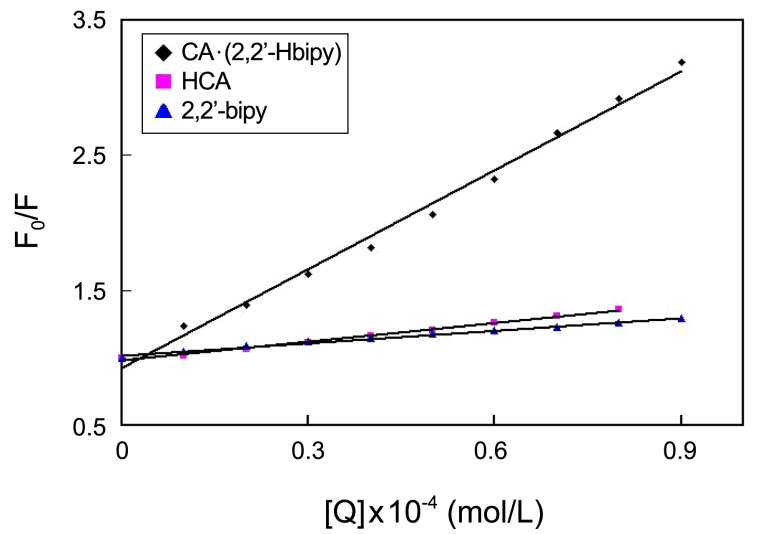

Figure 5. The Stern-Volmer curves of fluorescence quenching of BSA by CA.(2,2'-Hbipy), HCA and 2,2'-bipy at $24^{\circ} \mathrm{C}$.
Table 1. Stern-Volmer quenching constants for the interaction of compounds with BSA at $24{ }^{\circ} \mathrm{C}$

\begin{tabular}{cccc}
\hline Complex & CA $\left(2,2^{\prime}\right.$-Hbipy $)$ & HCA & 2,2'-bipy \\
\hline$K_{\mathrm{Sv}}\left(\mathrm{L} \cdot \mathrm{mol}^{-1}\right)$ & $2.4384 \times 10^{4}$ & $4.653 \times 10^{3}$ & $3.059 \times 10^{3}$ \\
$K_{\mathrm{q}}\left(\mathrm{L} \cdot \mathrm{mol}^{-1} \cdot \mathrm{S}^{-1}\right)$ & $2.4384 \times 10^{12}$ & $4.653 \times 10^{11}$ & $3.059 \times 10^{11}$ \\
$\mathrm{r}^{2}$ & 0.9922 & 0.9936 & 0.9900 \\
\hline
\end{tabular}

dynamic collision but complex-BSA formation. In other word, the fluorescence quenching of BSA mainly result from complexes formation and governed by a static quenching mechanism, while from dynamic collision could be
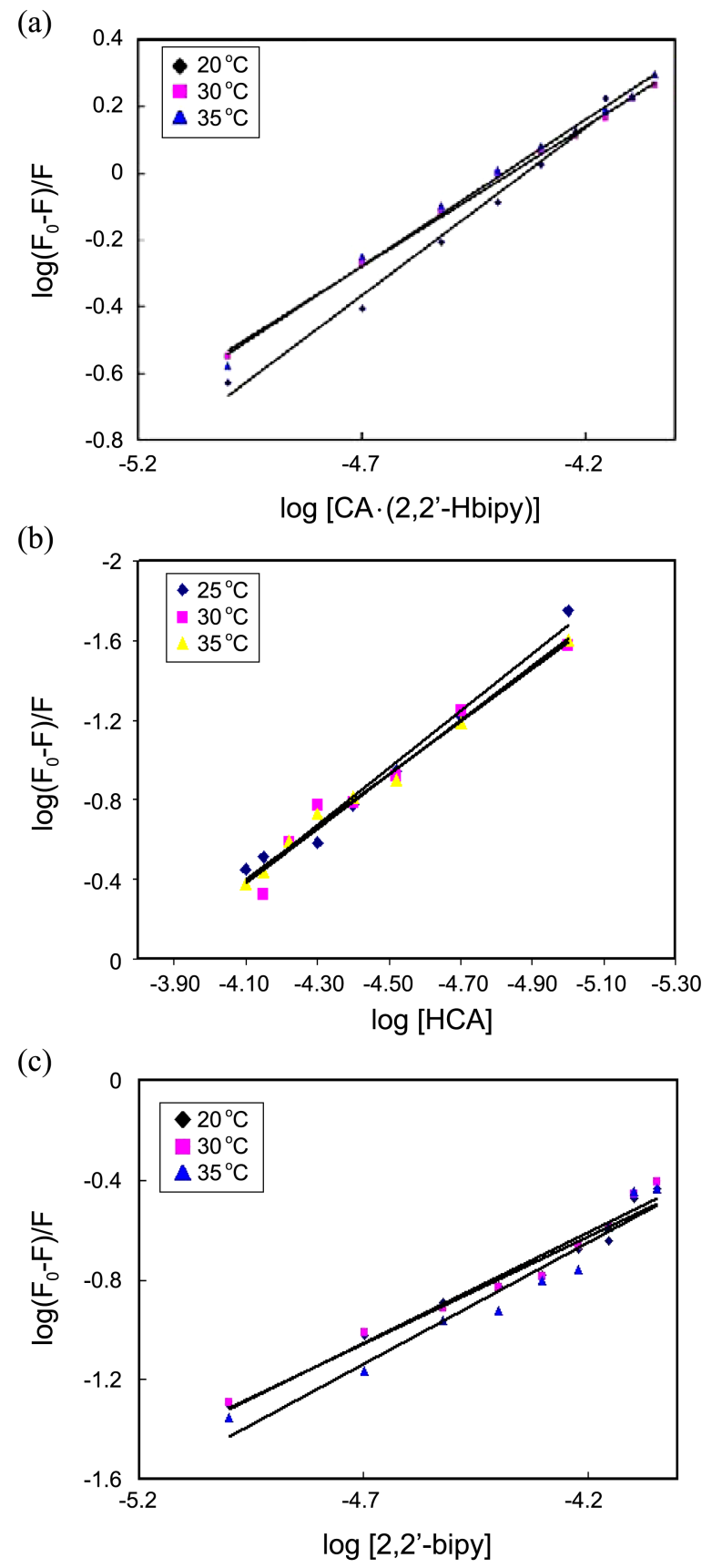

Figure 6. Double-log plot of CA $\left(2,2^{\prime}-\right.$ Hbipy) (a); $\operatorname{HCA}(b)$ and 2,2'-bipy (c) quenching effect on BSA fluorescence at $24{ }^{\circ} \mathrm{C}, 30^{\circ} \mathrm{C}$, $35^{\circ} \mathrm{C}$. 
negligible in the concentration range studied. ${ }^{28}$

Calculation of Binding Constant. For static quenching, the relationship between fluorescence quenching intensity and the concentration of quenchers can be described by the modified form of the Stern-Volmer equation. ${ }^{29}$

$$
\log \left(F_{0}-F\right) / F=\log K_{\mathrm{b}}+\mathrm{n} \log [Q]
$$

Thus, fluorescence intensity data can also be used to obtain the binding constant $\left(K_{\mathrm{b}}\right)$ and the number of binding sites (n), which can be determined by the slope and the intercept of double logarithm regression cure of $\log \left(F_{0}-F\right)$ / $F$ versus $\log [Q]$ based on the Eq. (2).

The values of $K_{\mathrm{b}}$ and $\mathrm{n}$ at $24{ }^{\circ} \mathrm{C}, 30{ }^{\circ} \mathrm{C}$ and $35{ }^{\circ} \mathrm{C}$ were obtained from the double logarithm regression curve (Fig. 6).

Table 2 summarizes the values of $K_{\mathrm{b}}$ and $\mathrm{n}$ at each temperature studied. The $\mathrm{n}$ values are nearly 1 , which indicate the existence of a single binding site in BSA for compounds. The binding constant inversely correlated with temperatures for interactions of HCA with BSA, which may indicate forming an unstable compound, ${ }^{30}$ this means that higher temperatures should weaken the binding and the reaction is exothermic. However, for the interaction of 2,2'-bipy with BSA, the increasing trend of binding constant with increasing temperature, which suggest that the compound was stable and the reaction is endothermic. For CA.(2,2'-Hbipy) with BSA, the binding constants at $24{ }^{\circ} \mathrm{C}$ is greater than they are in the $30{ }^{\circ} \mathrm{C}$ and $35^{\circ} \mathrm{C}$, which suggest that maybe the 24 ${ }^{\circ} \mathrm{C}$ is the most proper temperature for the compound-BSA combining.

Binding Modes. The acting compound between small organic molecule and bio-molecule includes hydrogen bond, van der Waals force, electrostatic and hydrophobic interaction. ${ }^{31}$ The signs and magnitudes of thermodynamic parameters $(\Delta H$ and $\Delta S)$ for protein reactions can account for the main forces contributing to protein stability. Both the $\Delta H$ and $\Delta S$ are positive imply a hydrophobic interaction; contrary, both the negative parameters of $\Delta H$ and $\Delta S$ show the van der Waals forces or hydrogen bond formation; when $\Delta S>0$ and $\Delta H \approx 0$ indicate an electrostatic force. ${ }^{32}$ For this reason, the temperature dependence on the binding constant was studied at three different temperatures (24, 30 and 35 ${ }^{\circ} \mathrm{C}$ ). The thermodynamic parameters could be calculated on the basis of the van't Hoff equation:

$$
\ln k=-\frac{\Delta H}{R T}+\frac{\Delta S}{R}
$$

$K$ is the binding constant at temperature $T$ and $R$ is gas constant. The value of $\Delta H$ and $\Delta S$ were obtained from linear van't Hoff plot. The free energy change $(\Delta G)$ can be estimated from the following relationship:

$$
\Delta G=\Delta H-\mathrm{T} \Delta S
$$

The results are presented in Table 3 . The negative $\Delta G$ revealed that the binding processes are spontaneous for the three compounds. For the formation of HCA-BSA coordination compounds, the negative $\Delta H$ and $\Delta S$ values showed that both hydrogen bond and van der Waals forces play a role in the binding process. ${ }^{33}$ For the formation of $\left(2,2^{\prime}-\right.$ bipy)-BSA complex, the fact that $\Delta H$ and $\Delta S$ are both positive suggest a strong contribution of the hydrophobic effect. From the negative values of $\Delta H\left(-96.698 \mathrm{KJ} \cdot \mathrm{mol}^{-1}\right)$ and the positive $\Delta S$ observed in the formation of $\mathrm{CA} \cdot\left(2,2^{\prime}-\right.$ Hbipy)-BSA, it can be concluded that it cannot be mainly attributed to electrostatic interactions since for electrostatic interactions $\Delta H$ is very small, almost zero. Negative $\Delta H$ value is observed whenever there is hydrogen bonding in the binding. So we can infer that both the electrostatic interactions and hydrogen bonding play a role in the binding process. $^{34}$

Conformation Investigation. The synchronous fluorescence spectra can provide very important information to study the microenvironment of amino acid residues by measuring the emission wavelength shift. The spectra were obtained through the simultaneous scanning of the excitation and the emission monochromators of a spectrofluorimeter, with a fixed wavelength difference $(\Delta \lambda)$ between them. ${ }^{35}$ When the $\Delta \lambda$ between excitation wavelength and emission wavelength was stabilized at 15 or $60 \mathrm{~nm}$, the synchronous fluorescence gave the characteristic information of tyrosine residues or tryptophan residues. ${ }^{36}$

In this work, the synchronous fluorescence spectra of BSA

Table 2. Binding constants and binding sites at three temperatures for the complex-BSA system

\begin{tabular}{|c|c|c|c|c|c|}
\hline Drug & $\begin{array}{c}\Delta G \\
24^{\circ} \mathrm{C}\left(\mathrm{KJ}^{2} \mathrm{~mol}^{-1}\right)\end{array}$ & $\begin{array}{c}\Delta G \\
30^{\circ} \mathrm{C}\left(\mathrm{KJ} \cdot \mathrm{mol}^{-1}\right)\end{array}$ & $\begin{array}{c}\Delta G \\
35^{\circ} \mathrm{C}\left(\mathrm{KJ} \cdot \mathrm{mol}^{-1}\right)\end{array}$ & $\Delta H\left(\mathrm{KJ} \cdot \mathrm{mol}^{-1}\right)$ & $\Delta S\left(\mathrm{KJ}^{-1} \cdot \mathrm{mol}^{-1}\right)$ \\
\hline CA $\cdot\left(2,2^{\prime}-\right.$ Hbipy $)$ & -25.296 & -22.862 & -21.645 & -96.698 & 234.56 \\
\hline HCA & -11.169 & -7.333 & -3.498 & -239.859 & -767.03 \\
\hline 2,2'-bipy & -16.434 & -18.707 & -19.843 & 50.187 & 227.26 \\
\hline
\end{tabular}

\begin{tabular}{ccccccc}
\hline \multirow{2}{*}{ Complex } & \multicolumn{2}{c}{$24^{\circ} \mathrm{C}$} & \multicolumn{2}{c}{$30^{\circ} \mathrm{C}$} & \multicolumn{2}{c}{$35^{\circ} \mathrm{C}$} \\
\cline { 2 - 7 } & $K_{\mathrm{b}}\left(\mathrm{mol} \cdot \mathrm{L}^{-1}\right)$ & $\mathrm{n}$ & $K_{\mathrm{b}}\left(\mathrm{mol} \cdot \mathrm{L}^{-1}\right)$ & $\mathrm{n}$ & $K_{\mathrm{b}}\left(\mathrm{mol} \cdot \mathrm{L}^{-1}\right)$ & $\mathrm{n}$ \\
\hline CA·(2,2'-Hbipy) & $4.114 \times 10^{4}$ & 1.0579 & $4.723 \times 10^{3}$ & 0.8412 & $7.278 \times 10^{3}$ & 0.8809 \\
HCA & $3.314 \times 10^{5}$ & 1.44 & $1.692 \times 10^{5}$ & 1.3677 & $1.044 \times 10^{5}$ & 1.3219 \\
2,2'-bipy & $9.17 \times 10^{2}$ & 0.855 & $1.260 \times 10^{3}$ & 0.8837 & $2.757 \times 10^{3}$ & 0.9737 \\
\hline
\end{tabular}

Table 3. Thermodynamic parameters of the benzodiazepines-BSA system 
(a)
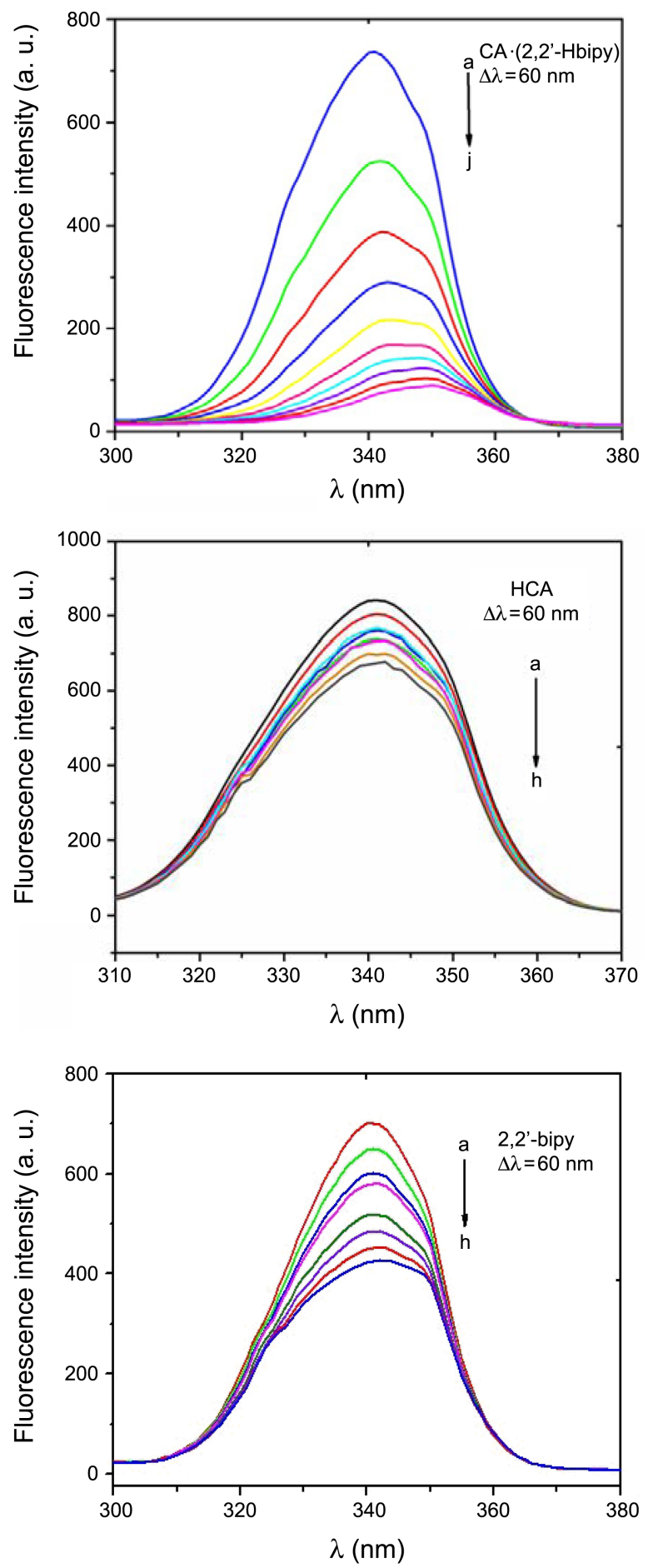

(b)
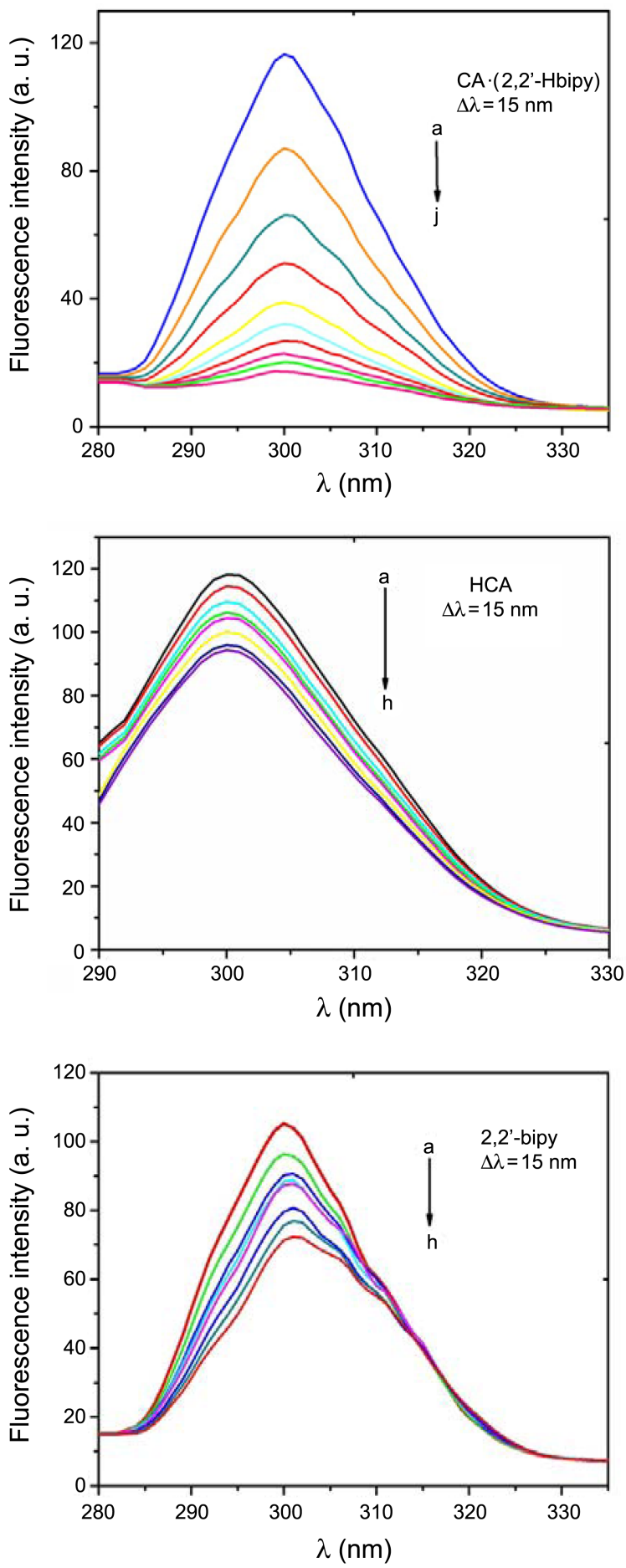

Figure 7. Synchronous fluorescence spectra of BSA: (a) $\Delta \lambda=60 \mathrm{~nm}$; (b) $\Delta \lambda=15 \mathrm{~nm}$. [BSA] $=1.00 \times 10^{-5} \mathrm{~mol} \cdot \mathrm{L}^{-1}$; [CA $\left.\cdot\left(2,2^{\prime}-\mathrm{Hbipy}\right)\right]$ : $0.00,0.50,1.00,1.50,2.00,2.50,3.00,3.50,4.00$ and $4.50 \times 10^{-5} \mathrm{~mol} \cdot \mathrm{L}^{-1}$; [HCA]: $0,2.50,5.00,7.50,10.00,12.50,15.00$ and 17.5 $\left(1.00 \times 10^{-5} \mathrm{~mol} \cdot \mathrm{L}^{-1}\right) ;\left[2,2^{\prime}\right.$-bipy]: $0.00,0.50,1.00,1.50,2.00,2.50,3.00$ and $3.50 \times 10^{5} \mathrm{~mol} \cdot \mathrm{L}^{-1}$.

at various complexes concentrations when $\Delta \lambda=60 \mathrm{~nm}$ and $\Delta \lambda=15 \mathrm{~nm}$ are shown in Figure 7. When $\Delta \lambda=60 \mathrm{~nm}$ [Fig. $7(\mathrm{a})]$, the addition of the complexes leads to a decrease in the synchronous fluorescence intensity with the red-shifts of the spectral peak. This indicates that the tryptophan residues increases, and it places in a less hydrophobic environment but more exposed to the solvent molecules during the binding process.37 Meanwhile, when the synchronous fluorescence spectra for $\Delta \lambda=15 \mathrm{~nm}$ (Fig. 7(b)), the emission peaks show essentially no shift over the investigated concentration range, which indicates that complexes have little effect on the micro-environment of tyrosine residues in the BSA. 


\section{Conclusions}

In summary, we have determined the crystal structure of the complexes formed by HCA and 2,2'-bipy with a 1:1 stoichiometry. The complex unit contains one 2,2'-Hbipy molecule and one $\mathrm{CA}$ molecule, the $\mathrm{CA}$ molecules are connected to each other through hydrogen bonds to form a 2D supra-molecular sheet. The 2,2'-Hbipy is adjunctive to the $2 \mathrm{D}$ sheet through the hydrogen bonds formed by carboxyl oxygen and a 2,2'-bipy nitrogen atom.

The results indicated that the fluorescence quenching mechanism of BSA by CA-(2,2'-Hbipy), HCA and (2,2'bipy) were consistent with the static model, and the binding reaction was spontaneous. Hydrogen bonds, hydrophobic forces and van der Waals forces played a major role in the complex-BSA interaction. Synchronous fluorescence spectra showed that the secondary structure of the BSA molecules was affected significantly in the presence of the complexes.

Acknowledgments. This work was supported by a grant from the National Natural Science Foundation of China (20962002, 20662001) and National Undergraduates Innovating Experimentation Project (091059314).

Appendix A. Supplementary Data. CCDC 818753 contains the supplementary crystallographic data for CA.(2,2'-Hbipy). The data can be obtained free of charge from The Cambridge Crystallographic Data Centre: http:// www.ccdc.cam.ac.uk/conts/retrieving.html.

\section{References}

1. Chen, J.; Sarma, B.; Evans J. M. B.; Myerson A. S. Cryst. Growth Des. 2011, in press.

2. (a) Sreekanth, B. R.; Vishweshwar, P.; Vyas, K.; Chem. Commun 2007, 2375. (b) Ling, A. R.; Baker, J. L. J. Chem. Soc., Trans. 1893, 63, 1314.

3. (a) Basavoju, S.; Boström, D.; Velaga, S. P. Pharm. Res. 2008, 25, 530. (b) Padrela, L.; Rodrigues, M. A.; Velaga, S. P.; Matosa, H. A.; Azevedo, E. G. Eur. J. Pharm. Sci. 2009, 38, 9.

4. (a) Shan, N.; Zaworotko, M. J. Drug Discov. Today 2008, 13, 440. (b) Vishweshwar, P.; McMahon, J. A.; Bis J. A.; Zaworotko, M. J. J. Pharm. Sci. 2005, 95, 499.

5. Childs, S. L.; Chyall, L. J.; Dunlap, J. T.; Smolenskaya, V. N.; Stahly, B. C.; Stahly, G. P. J. Am.Chem. Soc. 2004, 126, 13335.

6. Childs, S. L.; Hardcastle, K. I. Cryst. Growth Des. 2009, 7, 1291.

7. (a) Ravindrana, A.; Singha, A.; Raichurb, A. M.; Chandrasekaran, N; Jee, A. M. Colloid Surface B 2010, 76, 32. (b) Moreno, F.; Cortijo, M.; Jimenez, J. G. Photochem. Photobiol. 1999, 70, 695.

8. (a) Machicote, R. G.; Pacheco, M. E.; Bruzzone, L. Spectrochim. Acta A 2010, 77, 466. (b) Kang, J.; Liu, Y.; Xie, M.-X.; Li, S.; Jiang, M.; Wang, Y.-D. Biochim. Biophys. Acta 2004, 1674, 205.

9. Sklar, L. A.; Hudson, B. S.; Simoni, R. D. Biochemistry 1977, 16, 5100 .

10. (a) Joseph, K. S.; Hage, D. S. J. Chromatogr. B 2010, 878, 1590. (b) Wang, B.-S.; Fan, J.-L.; Sun, S.-G.; Wang, L.; Song, B.; Peng, X.-J. Dyes and Pigments 2010, 85, 43.

11. (a) Cao, S.-H.; Jiang, X.-Y.; Chen, J.-W. J. Inorg. Biochem. 2010, 104, 146. (b) Cho, C.-H.; Peng C.-C.; Chen, J.-H.; Wang, S.-S.; Tung, J.-Y. Polyhedron 2010, 29, 1116. (c) Wang, H.-J.; Wang, K.;
Yang, L.; An, Y.-G.; Cao, Y. Mater. Lett. 2010, 64, 181.

12. (a) Zhao, J.-Y.; Ren, F.-L. Spectrochim. Acta A 2009, 72, 682. (b) Chen, X.-T.; Xiang,Y.; Tong, A. J. Talanta 2010, 80, 1952. (c) Joseph, K. S.; Hage, D. S. J. Chromatogr. B 2010, 878, 1590. (d) Xu, H.; Gao, S.-L.; Lv, J.-B.; Liu, Q.-W.; Zuo, Y.; Wang, X. J. Mol. Struct. 2009, 919, 334.

13. Katrahalli, U.; Jaldappagari, S.; Kalanur, S. S. Spectrochim. Acta A 2010, 75, 314.

14. Cokugras, A. N.; Bodur, E. Pestic. Biochem. Physiol. 2003, 77, 24.

15. Stephanie,V. E. P.; Harry, G.; Antonie, J. W. G. V.; Koningsveld, G. A. V.; Jong, G. A. H. D.; Voragen, A. G. J. J. Agric. Food Chem. 2003, 51, 5088 .

16. Harshadrai, M. R.; Sascha, R.; Peter, K. H.; Jurgen, K. Food Chem. 2002, 78, 443.

17. Martin, R.; Lilley, T. H.; Falshaw, C. P.; Haslam, E.; Begley, M. J.; Magnolato, D. Phytochemistry 1987, 26, 273.

18. Martin, R.; Lilley, T. H.; Bailey, N. A.; Falshaw, C. P.; Haslam, E.; Magnolato, D.; Begleyc, M. J. J. Chem. Soc. Chem. Commun. 1986, 105.

19. Huang, L.; Lei, T.; Lin, C.-W.; Kuang, X.-C.; Chen, H.-Y.; Zhou, H. Fitoterapia 2010, 81, 389

20. Sheldrick, G. M. SADABS. 1996 (Program for Empirical Absorption Correction of Area Detector, University of Göttingen, Germany).

21. Sheldrick G. M. SHELXTL V5.1 Software Reference Manual, Bruker AXS, Inc., Madison, Wisconsin, USA. 1997.

22. Synthesis CA-(2,2'-Hbipy): To an ethanol aqueous solution (5 $\mathrm{mL}$ ) of chlorogenic acid HCA (35.4 mg, $0.1 \mathrm{mmol})$ was added an ethanol solution $(10 \mathrm{~mL})$ of 2,2'-bipyridine (2,2'-bipy) $(19.82 \mathrm{mg}$, $0.1 \mathrm{mmol}$ ), the mixture was left for evaporating at room temperature to obtain yellow block crystal after several days. Anal. Calcd for $\mathrm{C}_{26} \mathrm{H}_{26} \mathrm{~N}_{2} \mathrm{O}_{9}(\%)$ : C, 61.17; H, 5.13; N, 5.49. Found: C, 61.23; H, 5.20; N, 5.40.

23. Papadopoulou, A.; Green, R. J.; Frazier, R. A. J. Agric. Food Chem. 2005, 53, 158.

24. (a) Etzkorn, C.; Horton, N. C. Biochemistry 2004, 43, 13256. (b) Pinto, E. M.; Soares, D. M.; Brett, C. M. A. Electrochim. Acta 2008, 53, 7460. (c) Sucharita, D.; Arumay, P.; Chakrabarti, Janin, P. J. J. Mol. Biol. 2010, 398, 146. (d) Cao, S.-H.; Jiang, X.-Y.; Chen, J.-W. J. Inorg. Biochem. 2010, 104, 146. (e) Ding, F.; Liu, W.; Liu, F.; Li, Z.-Y.; Sun, Y. J. Fluoresc. 2009, 19, 783.

25. Lakowicz, J. R. Principles of Fluorescence Spectroscopy, 3rd ed.; Springer: New York, 2006.

26. Lakowicz, J. R.; Weber, G. Biochemistry 1973, 12, 4161.

27. (a) Hu, Y.-J.; Liu, Y.-L.; Zhang, X.; Zhao, R.-M.; Qu, S.-S. J. Mol. Struct. 2005, 750, 174. (b) Liu, Y.-M.; Li, G.-Z.; Sun, X.-F. Chin. J. Anal. Chem. 2004, 32, 615.

28. (a) Xu, H.; Gao, S.-L.; Lv, J.-B.; Liu, Q.-W.; Zuo, Y.; Wang, X. J. Mol. Struct. 2009, 919, 334. (b) Ge, F.; Chen, C.-Y.; Liu, D.-Q.; Han, B.-Y.; Xiong, X.-F.; Zhao, S.-L. J. Lumin. 2010, 130, 168.

29. Anbazhagan, V.; Renganathan, R. J. Lumin. 2008, 128, 1454.

30. Han, X.-L.; Mei, P.; Liu, Y.; Xiao, Q.; Jiang, F.-L.; Li, R. Spectrochim. Acta A 2009, 74, 781.

31. Leckband, D. A. Annu. Rev. Biophys. Bio. Mol. Struct. 2000, $29,1$.

32. Ross, P. D.; Subramanian, S. Biochemistry 1981, 20, 3096.

33. Timasheff, S. N. Thermodynamic of Protein Interactions; Peeters, H., Ed.; In Proteins of Biological Fluids; Pergamon Press: Oxford, 1972.

34. Ding, F.; Liu, W.; Liu, F.; Li, Z.-Y.; Sun, Y. J. Fluoresc. 2009, 19, 783.

35. Congdon, R. W.; Muth, G. W.; Splittgerber, A. G. Anal. Biochem. 1993, 213, 407.

36. Wang, T.-H.; Zhao, Z.-M.; Wei, B.-Z.; Zhang, L.; Ji, L. J. Mol. Struct. 2010, 970, 128.

37. Hu, Y.-J.; Liu, Y.; Zhao, R.-M.; Dong, J.-X.; Qu, S.-S. J. Photochem. Photobiol. A Chem. 2006, 179, 324. 